\title{
Long-Time Persistence of Superantigen-Producing Staphylococcus aureus Strains in the Intestinal Microflora of Healthy Infants
}

\author{
ERIKA LINDBERG, FOROUGH NOWROUZIAN, \\ INGEGERD ADLERBERTH, AND AGNES E. WOLD \\ Department of Clinical Immunology, Göteborgs University, SE-413 46 Göteborg, Sweden
}

\begin{abstract}
ABS
Staphylococcus aureus has been isolated at an increasing rate
from infants' stools during the last decades, but it is not known
whether this species can colonize and persist in the intestinal
microflora. To investigate this, 49 Swedish infants were followed
prospectively from birth until 12 months of age. $S$. aureus was
identified in a rectal swab obtained 3 d after delivery and in
quantitative cultures of fecal samples collected at 1,2 , 4 , and 8
weeks and at 6 and 12 months of age. A random amplified
polymorphic DNA (RAPD) method was developed to distinguish
individual $S$. aureus strains from one another and the strains were
tested for production of enterotoxins A-D and TSST-1. By 3 days
of age, $16 \%$ of infants had $S$. aureus in their intestines, which
increased to $73 \%$ by $2-6$ months, whereafter it decreased slightly
to $53 \%$. At the same time $S$. aureus population counts in colo-
nized infants declined from an average $10^{6.8}$ CFU/g feces during
the first months of life to $10^{4.0}$ CFU/g feces by 12 months.
Colonized infants usually harbored one or two $S$. aureus strains
\end{abstract}
Bacteria start to colonize the skin, respiratory tract, and intestines as soon as the newborn has left the sterile womb. With time, a complex ecosystem develops known as the normal microflora (1). Staphylococcus aureus colonizes the anterior nares of more than $50 \%$ of young infants (2-5). During the last decades, $S$. aureus has also been isolated at an increasing rate from fecal samples of infants in Western societies. Thus, only 1 out of 13 infants had $S$. aureus in their stools in a study performed in England in the 1980s (6), but 30\% in a Swedish study published 1985 (7) and 53\% in Sweden in the late 1990s (8). It is not known whether staphylococci persist and replicate in the intestines or if $S$. aureus in the stools represent bacteria transiently passing the intestines after having been swallowed.

Received March 15, 2000; accepted July 13, 2000.

Correspondence: Erika Lindberg, Department of Clinical Immunology, Guldhedsgatan 10, SE-413 46 Göteborg, Sweden

The study was supported by grants from the Swedish Foundation For Health Care Sciences and Allergy Research, the Asthma and Allergy Foundation, the Ellen, Walter and Lennart Hesselman Foundation, the TH Berg Foundation and the Swedish Medical Society. in their microflora for long periods of time. Few strains were transient passengers and the median time of persistence of $S$. aureus strains in the microflora was several months. Of the $75 \mathrm{~S}$. aureus strains identified, $43 \%$ produced one or more toxins: $13 \%$ SEA, $7 \%$ SEB, $23 \%$ SEC, $4 \%$ SED, and 11\% TSST-1. Altogether, $47 \%$ of the investigated infants were colonized by a toxin-producing $S$. aureus during their first year of life. Despite this they were apparently healthy and did not have more gastrointestinal problems than noncolonized infants. This report is the first to show that $S$. aureus may be a resident member of the normal intestinal microflora in infancy. (Pediatr Res 48: 741747, 2000)
Abbreviations
CFU, colony-forming units
TSST-1, toxic shock syndrome toxin-1
RAPD, random amplified polymorphic DNA

If infants are colonized by $S$. aureus in their intestines, it may have medical consequences. $S$. aureus strains can produce a range of different exotoxins, among them the enterotoxins, which cause vomiting with or without diarrhea and are responsible for staphylococcal food poisoning (9). The enterotoxins, together with toxic shock syndrome toxin-1, also function as "superantigens." By binding to both the $\mathrm{V} \beta$ chain of $\mathrm{T}$ cell receptors and to $\mathrm{MHC}$ class II molecules on antigen presenting cells they activate a broad range of $\mathrm{T}$ cells in an antigen nonspecific manner, resulting in massive cytokine secretion (9). Superantigen-producing $S$. aureus cause toxic shock syndrome, which was first recognized in children (10) and later in tampon-using women (11). S. aureus toxins with superantigen function have also been implicated in atopic dermatitis (12), sudden infant death $(13,14)$, and Kawasaki disease $(15,16)$ although the evidence is circumstantial. Due to their strong effects on the immune system, superantigen-producing $S$. $a u$ reus could theoretically play a role in the shaping of the infant's lymphoid system. In this context, it is interesting to note that the rising incidence of allergies in Western countries 
has been suggested to be linked to an altered intestinal colonization pattern $(17,18)$.

Intestinal colonization of an individual may be assessed by quantitative cultures of fecal samples and by determination of persistence of individual bacterial strains in the microflora. High numbers of fecal bacteria are not likely to be the result of contamination from skin flora or ingestion of bacteria. A strain which is present in the intestinal microflora of an individual for at least three weeks can be assumed to have colonized that individual, because a nonreplicating agent would have been eliminated during this time period (19). Thus, to determine whether a bacterial species represents a true colonizer of the intestinal tract or not, individual strains of the species must be distinguished from one another.

S. aureus strains have been typed using restriction fragment length polymorphism (RFLP) and pulse field gel-electrophoresis (PFGE) (20), methods that are time consuming and expensive, and by phage typing that has limited discriminatory capacity. Random amplified polymorphic DNA assay (RAPD) is a PCR-based method that in principle can be applied to all bacterial species (21). No prior knowledge of the gene sequence is needed. Short primers of arbitrary sequence are allowed to bind to bacterial DNA under low stringency conditions. By PCR, a series of DNA fragments of varying length are generated, the pattern of which form a "fingerprint" of a strain (21).

The aim of the study was to determine colonization rates and population counts of $S$. aureus in a group of Swedish infants followed prospectively from birth to 1 year of age. A RAPD method was developed to enable identification of individual strains of $S$. aureus in the microflora and thereby to assess their persistence. We also determined whether these $S$. aureus strains produced enterotoxins and/or TSST-1.

\section{MATERIALS AND METHODS}

Infants. Forty-nine healthy Swedish infants born in 1998-99 at Mölndal Hospital in Sweden (3500 deliveries/y) were studied. These children formed part of a prospective birth-cohort study aiming to investigate the relation between intestinal colonization pattern in infancy and later allergy development. Thirty-nine of the infants had at least one parent with atopy, while 10 infants had no allergic parent. In addition to regular sampling of the rectal flora, the feeding pattern and health status of the infants were continuously registered by the parents on questionnaires kept in their homes. The records were checked by a study nurse who interviewed the parents by telephone when the infants were 6 and 12 months old. The study was approved by the Medical Ethics Committee of Göteborg University.

All infants but five were vaginally delivered. Mothers and infants stayed in the maternity ward for $2-3 \mathrm{~d}$, where rooming-in was practiced. All infants were breast-fed from birth. At 1 month of age $80 \%$ were still exclusively breast-fed, and by 4 months, $73 \%$. By six months all infants received additional feeds, but partial breast-feeding was still practiced by $67 \%$.

Sampling and analysis of intestinal microflora. A rectal swab was obtained $3 \mathrm{~d}$ after delivery. The swab was streaked on agar selective for staphylococci (Staphylococcus medium No. 110) and cultured aerobically at $37^{\circ} \mathrm{C}$ for $2 \mathrm{~d}$ to determine the presence of staphylococci. S. aureus was identified as specified below.

Quantitative cultures of the fecal flora were performed at 1, 2,4 , and 8 wk and at 6 and 12 months of age. Feces was collected by the parents and put in a sterile Petri dish. The dish was placed in a gas-tight cachet together with an anaerobic generator (Becton Dickinson, Labfab, Sweden), an anaerobic indicator (Oxoid, Hampshire, England) and a damp sponge. The bag was kept refrigerated until being transported to the laboratory, where it was processed within $24 \mathrm{~h}$ after collection. Extensive preliminary experiments were performed to ensure that the procedure described above yielded the same results as immediate processing of fecal samples. No alternations in numbers of any of the important groups of aerobic or anaerobic bacteria could be demonstrated during the 24-storage period using this protocol.

Fecal samples were diluted serially in 10-fold steps in peptone-water and cultivated aerobically on Staphylococcus medium No. 110 at $37^{\circ} \mathrm{C}$ for $2 \mathrm{~d}$. The lowest level of detection was $400 \mathrm{CFU}$ (colony forming units)/g feces. Colonies of different morphology were isolated, subcultured on blood agar, Gram-stained and tested for catalase production (22). Isolates with typical Gram-stain appearance and positive catalase test were tested for coagulase production. Coagulase-positive isolates were regarded as $S$. aureus and frozen at [minus] $70^{\circ} \mathrm{C}$ until further analyzed.

Randomly amplified polymorphic DNA (RAPD) assay for typing of S. aureus strains. For development and optimization of the RAPD typing method, 10 different $S$. aureus strains from the culture collection of the University of Göteborg (CCUG numbers: 9,128, 10,777, 10,778, 15,915, 17,621, 25,925, 25,926, 26,215, 32,981, and 32,982) were used.

Bacterial DNA was isolated using the modified Insta Gene protocol (Bio-Rad Hercules, CA, U.S.A.) described by Jayarao et al. (23). $1.5 \mathrm{~mL}$ of an overnight brain heart infusion broth culture was centrifuged at $17,000 \times g$. The bacteria were washed in TE-buffer (10 mM Tris-HCl, $1 \mathrm{mM}$ EDTA, $\mathrm{pH} 8$, Sigma-Aldrich, Stockholm, Sweden) and suspended in $0.2 \mathrm{~mL}$ of Insta Gene matrix (Bio-Rad Hercules). The mixture was incubated at $56^{\circ} \mathrm{C}$ for $30 \mathrm{~min}$ followed by $99^{\circ} \mathrm{C}$ for $10 \mathrm{~min}$ and centrifuged at $17000 \times g$ for $5 \mathrm{~min}$. The supernatant DNA concentration was determined by absorbance $260 \mathrm{~nm}$ (LKB Biochrom, Ultrospec II, Cambridge, Great Britain).

The following 10-mer oligonucleotide primers were tested: 5'CAGCACCCAC-3' (OPA-13, Kit A, Operon Technologies, Alameda, CA, U.S.A.) (23), 5'-GTGATCGCAG-3'(OPA-10, Kit A, Operon Technologies), 5'-GTGACATGCC-3' (OPE-4, Kit E, Operon Technologies) (23), 5'-AACGGTGACC3'(OPE-20, Kit E, Operon Technologies) (23), 5'-CCGGCGGCG-3'(Pharmacia Biotech, Uppsala, Sweden) (24) and 5'ACGCGCCCT-3' (Pharmacia Biotech, Sweden) (25). Primer OPE-20 was found to give reproducible results and to allow clear distinction between different strains of $S$. aureus.

Amplification of bacterial DNA was performed in PCRbuffer mixture with a total volume of $50 \mu \mathrm{L}$, containing optimal amounts of the different reactants which were found to 
be: 8 pmol primer (6-12 pmol tested), 10 ng bacterial DNA (10-40 ng tested), $0.2 \mathrm{mmol}$ dNTP (0.1-0.4 mmol tested), 3.5 $\mathrm{mmol} \mathrm{MgCl}_{2}$ (1.5-5.5 mmol tested). Distilled water was added to reach a volume of $50 \mu \mathrm{L}$. The tube was sealed by a drop of mineral oil and heated to $80^{\circ} \mathrm{C}$ in a Thermocycler (Perkin Elmer Cetus Model 480, NJ, U.S.A.), whereafter 3U Taqpolymerase (2-3.5 U tested) was added and the temperature risen to $94^{\circ} \mathrm{C}$ for $120 \mathrm{~s}$ for denaturation. 35 PCR cycles were run, each consisting of incubation at $94^{\circ} \mathrm{C}$ for $70 \mathrm{~s}$, at $33^{\circ} \mathrm{C}$ for $60 \mathrm{~s}$, and at $72^{\circ} \mathrm{C}$ for $130 \mathrm{~s}(23)$.

The PCR products were separated by PAGE. Ready made $8 \%$ Tris-Glycine gels (Novex, Frankfurt, Germany) were applied in a vertical electrophoresis apparatus (Novex). Samples and DNA marker (Boehringer Mannheim, Bromma, Sweden) were loaded on the gel and the electrophoresis was run using Tris-Glycine as running buffer $(0.24 \mathrm{M}$ Trisbase, $1.9 \mathrm{M}$ glycine, $0.035 \mathrm{M} \mathrm{SDS}, \mathrm{pH} 8.3$ ) at a constant voltage of $90 \mathrm{~V}$ for $2 \mathrm{~h}$ 15 min. DNA was visualized by silver staining (Plusone DNA silver staining kit, Pharmacia Biotech, Uppsala, Sweden), whereafter the gels were dried (Dry Ease Gel Drying System, Novex).

Toxin production by $S$. aureus strains. One isolate of each S. aureus strain was cultivated overnight in broth and tested for toxin-production by reversed passive latex agglutination. The SET-RPLA kit was used to detect enterotoxin A, B, C, and D and the TST-RPLA kit for TSST-1 (both from Oxoid, Hampshire, Great Britain).

Statistics. Frequencies were compared using Fisher's exact test. Bacterial numbers were compared using Wilcoxon's ranksum test.

\section{RESULTS}

Colonization frequency and population levels of $\mathrm{S}$. aureus. The isolation rate of $S$. aureus in the intestinal microflora of 49 infants is shown in Figure 1. Sixteen percent of the infants were culture-positive for $S$. aureus by day 3 . Thereafter, colonization rates increased continuously to reach $73 \%$ by 6 mo. By 12 months of age $53 \%$ still had S. aureus in their stool samples. The decrease in colonization rate between 6 and 12 mo was not quite significant $(p=0.06)$.

Fecal counts of $S$. aureus in culture positive infants are shown in Figure 2. S. aureus population numbers declined continuously throughout the period, from almost $10^{7} \mathrm{CFU}$ (colony-forming units) per $\mathrm{g}$ feces during the first month to $10^{4}$ $\mathrm{CFU} / \mathrm{g}$ feces by 1 year of age. The decline in $S$. aureus population numbers was significant between 2 and 6 mo $(p=$ $0.0004)$, as well as between 6 and $12 \mathrm{mo}(p=0.0001)$. There was no difference in $S$. aureus colonization pattern between infants born to atopic or nonatopic parents (data not shown).

Typing of S. aureus isolates obtained from the intestinal flora of infants. The RAPD method for strain typing of $S$. aureus was applied to 262 isolates obtained from the 42 infants who had $S$. aureus in at least one sample.

Figure 3 shows examples of the RAPD patterns of $S$. aureus isolates from three of the infants (children Nos. 1, 5, and 6). Child No. 1 carried two strains during the study period, strain A being represented by seven isolates, and strain B by two



Figure 1. Intestinal S. aureus colonization rate in 49 Swedish infants. The 3-day sample consisted of a rectal swab, the rest were fecal cultures in which the limit of detection was $400 \mathrm{CFU} / \mathrm{g}$ feces $\left(10^{2.6}\right)$.

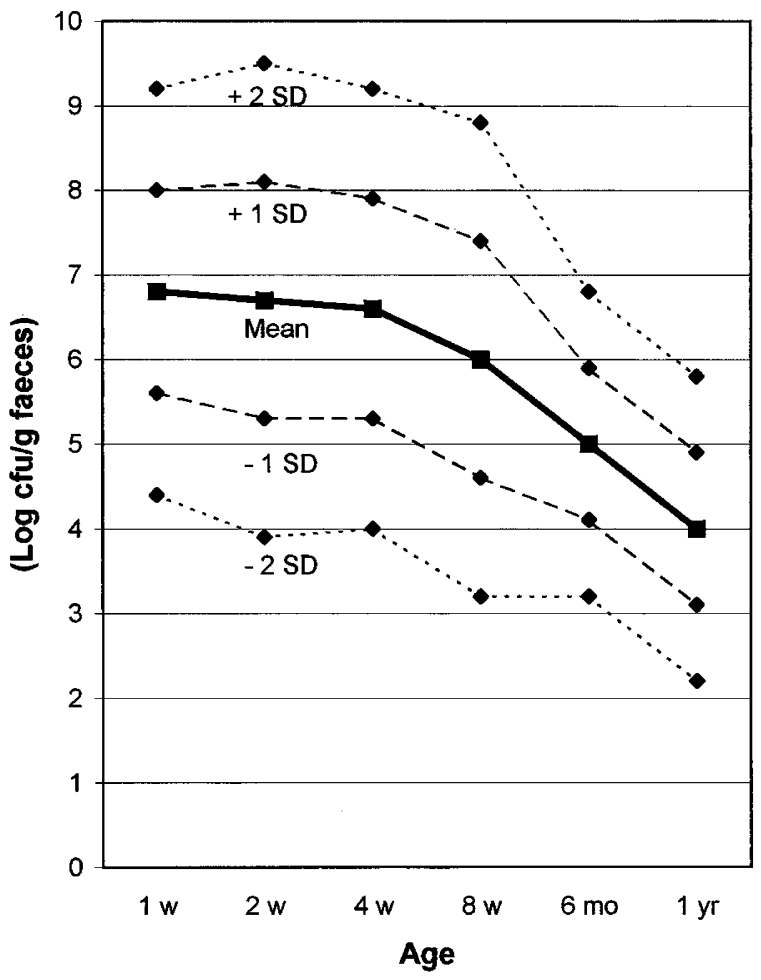

Figure 2. S. aureus population counts in fecal samples from culture-positive infants.

isolates (Fig. 3a). Child 5 carried a single S. aureus strain (A) on all occasions (Fig. 3b). Child 6 carried two strains, strain A being represented by three isolates, strain $\mathrm{B}$ by a single isolate (Fig. 3b). As evident from the figure, the RAPD patterns could easily be distinguished from one another by the naked eye. Although we did not directly compare RAPD patterns between 

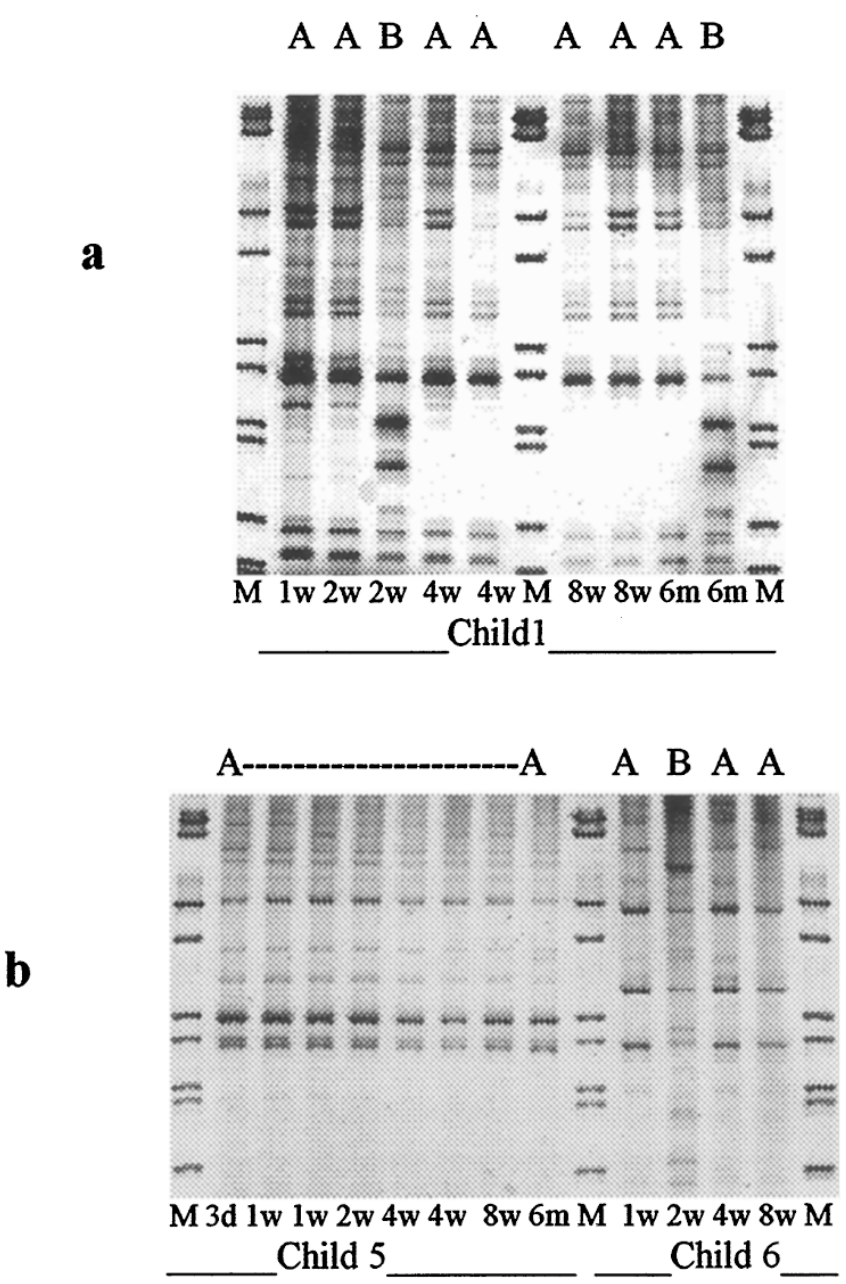

Figure 3. $(A)$ and $(B)$ : RAPD patterns of $S$. aureus isolates from the intestinal microflora of three children. The first strain appearing in a child is termed $A$, the second $B . \mathrm{M}=$ molecular weight standard. The same children appear also in Fig. 4 (Nos. 1, 5, and 6).

infants, we did not observe two identical RAPD patterns in strains obtained from different infants, suggesting that all identified strains were different. Reproducibility was tested by reanalyzing the same strains by PCR a number of times. The electrophoretic patterns obtained were very similar for the same strain and the strains could always easily be distinguished from one another (data not shown).

The longitudinal $S$. aureus colonization patterns of the first 14 infants is shown in Figure 4. As seen in figure, most of them carried one or two $S$. aureus strains for long periods of time. In several instances, a strain was present in the microflora of an infant, then absent from one or several samples, and then appeared again (a dashed line in figure). Only rarely was a strain present on a single sampling occasion only (strains marked with an asterisk), and in these cases they were found at either the 6 or 12 month sampling occasions, in which case they could have been present for quite some time between the samplings. In the total cohort of 42 culture positive infants, $54 \%$ had a single $S$. aureus strain in the microflora during their first 6 months of life, $39 \%$ of the infants carried two strains and $7 \%$ three strains.
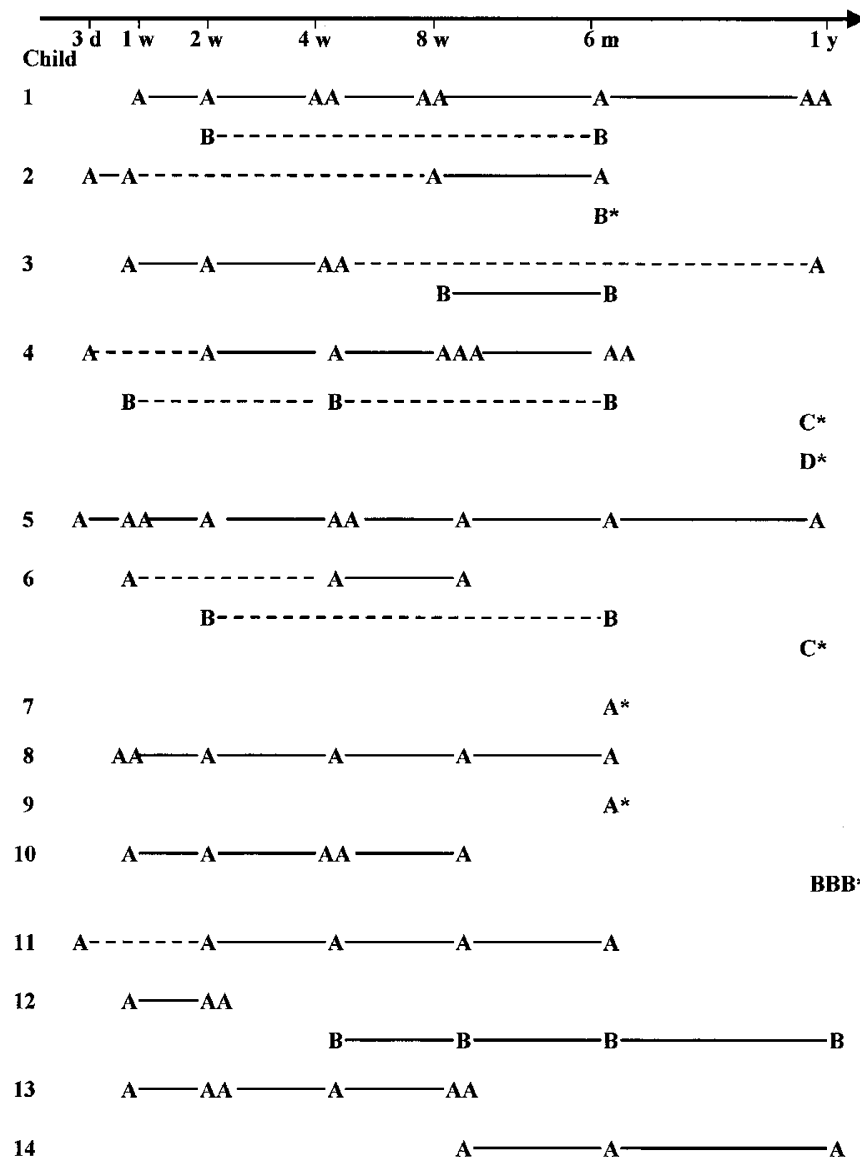

Figure 4. Colonization patterns of 14 children culture positive for S. aureus on at least one occasion during their first 12 mo of life. In each infant, the different strains identified are labeled $A, B, C$, and $D$ in their order of appearance. Each letter represents one isolate of the strain. A solid line indicates the continuous presence of the strain in the microflora since it was detected on all culture occasions, a dashed line denotes that the strain was not found on an intervening occasion. An asterisk marks a strain only found once in an infant.

Resident strains were defined as those present in the microflora consecutively for at least 3 weeks. These calculations were made only on the period up to 6 mo, because sampling occurred with too long intervals after this time. Out of the 63 strains identified in 41 infants between 0 and 6 mo age, 15 were of undetermined colonizing capacity, because they were found only in the 6-month sample in which case one cannot know whether the strain would occur at later time-points. Of the remaining 48 strains, 35 (73\%) were resident, while only 13 $(23 \%)$ were transient. The median time of persistence of resident strains was at least $17 \mathrm{wk}$ (range $3 \mathrm{w}-\geq 6 \mathrm{mo}$ ), the median time of persistence of all strains was $11 \mathrm{wk}$ during this time period.

Of the infants who had S. aureus in their microflora by 6 months, one third retained this strain by $12 \mathrm{mo}$, one third acquired a new $S$. aureus strain between 6 and $12 \mathrm{mo}$, and another third lost $S$. aureus from their microflora after 6 mo.

Toxin production by intestinal S. aureus strains. One isolate each of the 75 identified $S$. aureus strains was tested for toxin production. Forty-three percent produced one or more toxins: $13 \%$ enterotoxin $\mathrm{A}, 7 \%$ enterotoxin $\mathrm{B}, 23 \%$ enterotoxin 
C, 4\% enterotoxin D, and 11\% TSST-1. Twenty-eight percent of the strains produced more than one toxin, most commonly an enterotoxin in combination with TSST-1. Altogether, 23 of the 49 infants $(47 \%)$ harbored a toxin-producing strain of $S$. aureus in their intestinal microflora during their first 12 months of life.

Toxin production was related to colonization levels and time of persistence in the microflora. Overall, 25\% of the toxin producing strains and $16 \%$ of the nonproducing strains reached a colonization level of $>10^{8}$ CFU/g feces (N.S). Fifty-six percent of toxin producing strains were resident, i.e. persisted at least $3 \mathrm{wk}$, compared with $44 \%$ of nontoxin producing strains (N.S).

Clinical characteristics of colonized infants. Gastrointestinal problems were reported in nine infants. The symptoms included diarrhea (two infants), colic (three infants), constipation (two infants) and abdominal pain (four infants). All these nine infants were colonized by $S$. aureus, but only three of them by toxin-producing strains (1 SEC, 1 SEC-TSST-1, 1 SED). Thus, we did not detect any overt clinical consequences of intestinal colonization by toxin-producing $S$. aureus.

\section{DISCUSSION}

In the present study, we have demonstrated that $S$. aureus has become a major colonizer of the intestinal tract of Swedish infants. More than $80 \%$ of the infants studied had $S$. aureus in their stool samples at any time during their first year of life. Between 2 and 6 months of age, when colonization rate was maximal, three children out of four had $S$. aureus in their intestinal microflora at any point in time. Although colonization declined somewhat after 6 months of age, approximately $50 \%$ of the infants were still culture-positive by 12 months of age. The possibility that this represented contamination by skin flora during sampling or by swallowed $S$. aureus from nasal secretion was negated by the high population counts (median $10^{6.7} \mathrm{CFU} / \mathrm{g}$ feces by 1 month of age). Furthermore, contrary to the colonization pattern described here, nasal carriage of $S$. aureus is maximal in the perinatal period and decreases thereafter $(3,4)$.

The possibility that the bacteria were transient passengers present in the stools, e.g. because of intake of contaminated food, was negated by an average persistence of individual $S$. aureus strains in infants' flora of several months. Some $S$. aureus strains seemed to come and go in the microflora of an infant. Such strains were present during one or several samples, then absent to appear again at later time points. These strains might have been suppressed by other bacteria during a period, or they were simply missed during the isolation procedure because of the simultaneous presence in all infants of large numbers of coagulase negative staphylococci, which grew on the same plates. A third possibility is that the child was re-colonized by the same strain, possibly from someone in the family.

Among intestinal bacteria, only Escherichia coli has so far been studied with regard to longitudinal colonization patterns of individual strains. Certain strains, termed resident, persist in the microflora for months or years, while others, termed tran- sient, do not colonize but disappear from the flora in one or a few weeks' time (26-29). Swedish infants often carry a single resident $E$. coli strain in their microflora for many months and the transient strains are few (30). This has been attributed to low environmental exposure to $E$. coli, since infants born in Pakistan exhibit a rapid turnover of individual $E$. coli strains in their microflora (29). The stable $S$. aureus colonization pattern seen here is, thus, not indicative of an overwhelming exposure to this bacterial species. We instead suggest that $S$. aureus is so common in Swedish infants due to lack of competition with other bacterial groups better suited for colonization of the large bowel. Neonatal colonization with $E$. coli and other enterobacteria seems to have declined in Sweden during the last decades, most likely due to a generally increased hygiene and reduced spread of these bacteria in maternity wards (31) (Adlerberth et $a l$. in preparation). In accordance, $S$. aureus population levels were quite high during the 1 st month, but decreased progressively with time even if colonization continued. We noted a similar decrease in fecal counts of coagulase negative staphylococci with time, while the counts of Enterobacteriaceae and enterococci stayed high (unpublished observations). These findings implicate that staphylococci cannot compete favorably with more "traditional" intestinal bacteria when a more complex microflora develops.

We believe that the source of $S$. aureus colonizing the infants was the skin flora of the people in the infants' home milieu. Colonization was low by 3 d' age and increased continuously, which speaks against transfer at delivery or acquisition at the hospital, where these infants stayed only for 2-3 d. Moreover, we have in several instances observed strains with identical RAPD patterns on a mother's skin and in her infant's fecal samples (Lindberg, unpublished results). The very high frequency of long duration breast-feeding in Sweden could contribute to transfer of $S$. aureus from mother to infant. $S$. aureus is a more common colonizer of breast-fed than formula-fed infants, probably because these bacteria colonize the skin around the nipple and are swallowed during suckling (7, 32, 33).

Somewhat less than half of the $S$. aureus strains produced enterotoxin A, B, C, or D, and/or TSST-1, which is in accordance with previous studies that report a rate of toxin production of $30 \%$ to $50 \%$ in clinical isolates of $S$. aureus $(34-36)$. We found that enterotoxin $\mathrm{C}$ was the toxin most commonly produced, followed by enterotoxin A and TSST-1, while enterotoxins $\mathrm{B}$ and $\mathrm{D}$ were the least common ones. The dominance of enterotoxin $\mathrm{C}$ isolates is similar to what has been reported for human skin isolates of $S$. aureus $(34,37)$.

Enterotoxins induce vomiting and diarrhea and S. aureus enterotoxins share with TSST-1 the "superantigen" function. This means that they can activate a broad range of $\mathrm{T}$ cells resulting in massive cytokine production, a mechanism responsible for toxic-shock-syndrome (9). Despite this, infants colonized by toxin-producing strains were apparently healthy and did not have more gastrointestinal problems than others. The extent of expression of the toxins in situ in the intestine remains to be studied. The temperature in the intestinal lumen is $37^{\circ} \mathrm{C}$, which is optimal for toxin production (38). On the other hand, the oxygen content might be too low to enable their 
synthesis (38). However, if intestinal $S$. aureus gain entrance into the tissues by translocation across the intestinal barrier, they would most probably be able to produce toxins. Translocation of bacteria is proportional to bacterial population levels in the gut. For example, when E. coli population levels exceed $10^{8} / \mathrm{g}$ faces, live $E$. coli bacteria can be found in the mesenteric lymph nodes of experimental animals $(39,40)$. A number of the infants studied here were colonized by $S$. aureus strains reaching such high population levels during their 1 st weeks of life.

It is also possible that toxins are produced in vivo, but that their action is neutralized by antibodies present in breast-milk (41). Since practically all adults are sero-positive against $S$. aureus toxins and such antibodies are transferred via the placenta, anti-toxin antibodies should also be present in most infant sera (42-44). The fact that most infants have been exposed to toxin-producing $S$. aureus is indicated by findings of protective levels against the $S$. aureus toxin TSST-1 in 30\% of 2-year-old U.S. children (43).

$S$. aureus is one of the major causes of neonatal septicaemia in Sweden and other Western countries (45). Septicaemia due to enterobacteria has been suggested to result from direct translocation of the bacteria over the intestinal barrier because the same strain of $E$. coli or other enterobacteria can be isolated from both the blood and the intestinal microflora $(46,47)$. It is thus conceivable that septic isolates of $S$. aureus may in some cases derive from the intestinal microflora, rather than from the skin as has previously been assumed. In accordance, infants struck by $S$. epidermidis septicaemia often have $S$. epidermidis in their stools (48).

The fact that so many children carry $S$. aureus in their intestinal microflora, and that $S$. aureus strains may persist for several months in their intestines, has not been reported before. A low level of colonization with E. coli and maybe other groups of intestinal commensal bacteria has probably paved the way for $S$. aureus, which has previously not been recognized as a commensal intestinal species. Since this pattern of colonization is likely to have evolved during the last decades, the consequences for infant health remains to be studied.

\section{REFERENCES}

1. Adlerberth I, Hanson LÅ, Wold AE 1999 The ontogeny of the intestinal flora. In: Sanderson IR, Walker WA (eds) Development of Gastro-Intestinal Tract. B.C Decker, Hamilton, Ontario, pp 279-292

2. Aniansson G, Alm B, Andersson B, Larsson P, Nylen O, Peterson H, Rigner P, Svanborg M, Svanborg C 1992 Nasopharyngeal colonization during the first year of life. J Infect Dis $165: 38-42$

3. Blackwell CC, MacKenzie DA, James VS, Elton RA, Zorgani AA, Weir DM, Busuttil A 1999 Toxigenic bacteria and sudden infant death syndrome (SIDS): Nasopharyngeal flora during the first year of life. FEMS Immunol Med Microbiol 25:51-58

4. Harrison LM, Morris JA, Telford DR, Brown SM, Jones K 1999 The nasopharyngeal bacterial flora in infancy: effects of age, gender, season, viral upper respiratory tract infection and sleeping position. FEMS Immunol Med Microbiol 25:19-28

5. Vines M, Garcia ME, Saenz P, Mora MA, Mata L, Sabharwal H, Svanborg C 1997 Nasopharyngeal colonisation in Costa Rican children during the first year of life. Pediatr Infect Dis 9:852-858

6. Stark PL, Lee A 1982 The bacterial colonisation of the large bowel of pre-term low birth weight neonates. J Hyg (Camb) 89:59-67

7. Lundequist B, Nord CE, Winberg J 1985 The composition of the faecal microflora in breastfed and bottlefed infants from birth to 8 weeks. Acta Paediatr Scand 74:54-58

8. Sepp E, Julge K, Vasar M, Naaber P, Björkstén B, Mikelsaar M 1997 Intestinal microflora of Estonian and Swedish infants. Acta Paediatr 86:956-961

9. Dinges MM, Orwin PM, Schlievert PM 2000 Exotoxins of Staphylococcus aureus Clin Microbiol Rev 13:16-34
10. Todd J, Fishaut M, Kapral F, Welch T 1978 Toxic-shock syndrome associated with phage-group-1 staphylococci. Lancet 25:1116-1118

11. Reingold AL, Broome CV, Gaventa S, Hightower AW, Toxic Study Group 1989 Risk factors for menstrual toxic shock syndrome: results of multistate case-control study. Rev Infect Dis 11:S35-S41

12. Strickland I, Hauk PI, Trumble AE, Picker LJ, Leung DYM 1999 Evidence for superantigen involvement in skin homing of $\mathrm{T}$ cells in atopic dermatitis. J Invest Dermatol 112:249-253

13. Zorgani A, Essery SD, Madani OA, Bentley AJ, James VS, MacKenzie DA, Keeling JW, Rambaud C, Hilton J 1999 Detection of pyrogenic toxins of Staphylococcus aureus in sudden infant death syndrome. FEMS Immunol Med Microbiol 25:103-108

14. Malam JE, Carrick GF, Telford DR, Morris JA 1992 Staphylococcal toxins and sudden infant death syndrome. J Clin Pathol 45:716-721

15. Leung DYM, Meissner HC, Fulton DR, Murray DL, Kotzin BL, Schlievert PM 1993 Toxic shock syndrome toxin-secreting Staphylococcus aureus in Kawasaki syndrome. Lancet 342:1385-1388

16. Leung DYM, Sullivan KE, Brown-Whitehorn TF, Fehringer AP, Allen S, Finkel TH, Washington RL, Makida R, Schlievert PM 1997 Association of toxic shock syndrome toxin-secreting and exfoliative toxin-secreting Staphylococcus aureus with Kawasaki syndrome complicated by coronary artery disease. Pediatr Res 42:268-272

17. Björksten B, Naaber P, Sepp E, Mikelsaar M 1999 The intestinal flora in allergic Estonian and Swedish 2-year-old children. Clin Exp Allergy 29:342-346

18. Wold AE 1998 The hygiene hypothesis revised: is the rising frequency of allergy due to changes in the intestinal flora? Allergy 53:20-25

19. Wold AE 1999 Role of bacterial adherence in the establishment of the normal intestinal microflora In: Hanson LÅ, Yolken RH (eds) Probiotics, Other Nutritional Factors, and Intestinal Microflora. Lippincott-Raven, Philadelphia, pp 47-61

20. Tenover FC, Arbeit R, Archer G, Biddle J, Bryne S 1994 Comparison of traditional and molecular methods of typing isolates of Staphylococcus aureus. J Clin Microbiol 32:407-415

21. Tambic A, Power EGM, Talsania H, Anthony RM, French GL 1997 Analysis of an outbreak of non-phage-typable methicillin resistant Staphylococcus aureus by using randomly amplified polymorphic DNA assay. J Med Microbiol 35:3092-3097

22. Hansen SL, Stewart BJ 1978 A reliable test for identification and presumptive identification of certain clinically significant anaerobes. Am J Clin Pathol 69:36-40

23. Jayarao BM, Gillespie BE, Oliver SP 1996 Application of randomly amplified polymorphic DNA fingerprinting for species identification of bacteria isolated from bovine milk. J Food Protect 59:615-620

24. Mattews KR, Oliver SP 1994 Differentiation of Staphylococcus species by polymerase chain reaction-based DNA fingerprinting. J Food Protect 57:486-489

25. Johansson ML, Quednau M, Molin G, Ahrn'e S 1995 Randomly amplified polymorphic DNA (RAPD) for typing of Lactobacillus plantarum strains. Lett Appl Microbiol 21:155-159

26. Sears HJ, Brownlee I 1951 Further observations on the persistence of individual strains of Escherichia coli in the intestinal tract of man. J Bacteriol 63:47-57

27. Tullus K 1988 Faecal colonization with P-fibriated Escherichia coli between 0 and 18 months of age. Epidemiol Infect 100:185-191

28. Wold AE, Caugant DA, Lidin-Janson G, de Man P, Svanborg C 1992 Resident colonic Escherichia coli strains frequently display uropathogenic characteristics. J Infect Dis 165:46-52

29. Adlerberth I, Jalil F, Carlsson B, Mellander L, Hanson LÅ, Larsson P, Khalil K, Wold AE 1998 High turnover rate of Escherichia coli strains in the intestinal flora of infants in Pakistan. Epidemiol Infect 121:587-598

30. Kuhn I, Tullus K, Möllby R 1986 Colonisation and presistence of Escherichia coli phenotypes in the intestines of children aged 0 to 18 months. Infection 14:7-12

31. Adlerberth I, Carlsson B, de Man P, Jalil F, Khan SR, Larsson P, Mellander L, Svanborg C, Wold AE, Hanson LA 1991 Intestinal colonisation with Enterobacteriaceae in Pakistani and Swedish hospital-delivered infants. Acta Paediatr Scand 80:602-610

32. Balmer SE, Wharton BA 1989 Diet and faecal flora in the newborn; breastmilk and infant formula. Arch Dis Child 64:1672-1677

33. Simhon A, Douglas JR, Drasar BS, Soothill JF 1982 Effect of feeding on infants' faecal flora. Arch Dis Child 57:54-58

34. Hogevik H, Söderqvist B, Tung H-S, Olaison L, Westberg A, Ryden C, Tarkowski A, Andersson R 1998 Virulence factors of Staphylococcus aureus strains causing infective endocarditis - a comparison with strains from skin infections. APMIS 106:901-908

35. Lehn N, Shaller E, Wagner H, Krönke M 1995 Frequency of toxic shock syndrome toxin- and enterotoxin-producing clinical isolates of Staphylococcus aureus. Eur J Clin Microbiol Infect Dis 14:43-46

36. Melconian AK, Burn Y, Fleurette J 1983 Enterotoxin production, phage typing and serotyping of Staphylococcus aureus strains isolated from clinical materials and food. J Hyg (Lond) 91:235-242

37. Zdrazilek J, Petras P, Sramova H, Subertova V, Maskova L 1988 Staphylococcus aureus at maternity ward. I. Colonisation of mothers and neonates and survival of various $S$. aureus types in colonised individuals. J Hyg Epidemiol Microbiol Immunol 32:49-57

38. Schlievert PM, Blomster DA 1983 Production of staphylococcal pyrogenic exotoxin type C: influence of physical and chemical factors. J Infect Dis 147:236-242

39. Herias MV, Midtvedt T, Hanson LÅ, Wold AE 1995 Role of Escherichia coli in intestinal colonisation in gnotobiotic rats. Infect Immunol 63:4781-4789

40. Herias MV, Midtvedt T, Hanson LÅ, Wold AE 1997 Escherichia coli K5 capsule enhances colonisation of the large intestine in gnotobiotic rat. Infect Immunol 65:531-536 
41. Gordon AE, Saadi At, MacKenzie DA, Molony N, James VS, Weir DM, Busuttil A, Blackwell CC 1999 The protective effect of breast feeding in relation to sudden infant death syndrome (SIDS): III Detection of IgA antibodies in human milk that bind to bacterial toxins implicated in SIDS. FEMS Immunol Med Microbiol 25:175-182

42. McGann VG, Rollins JB, Mason DW 1971 Evaluation of resistance to staphylococcal enterotoxin B: naturally acquired antibodies of man and monkey. J Infect Dis 124:206-213

43. Vergeront JM, Stolz SJ, Crass BA, Nelson DB, Davis JP, Bergdoll MS 1983 Prevalence of serum antibody to staphylococcal enterotoxin $\mathrm{F}$ among Wisconsin Residents: implications for toxic-shock-syndrome. J Infect Dis 148:692-698

44. Al Madani O, Gordon AE, Weir DM, Raza MW, Busuttil A, Blackwell C 1999 Pyrogenic toxins of Staphylococcus aureus in sudden unexpected nocturnal deaths in adults and older children: factors influencing the control of inflammatory responses to toxic shock syndrome toxins. FEMS Immunol Med Microbiol 25:207-219

45. Bennet R, Eriksson M, Zetterström R 1981 Increasing incidence of neonatal septicemia: causative organism and predisponsing risk factors. Acta Paediatr Scand 70:207-210

46. van Camp JM, Tomaselli V, Coran AG 1994 Bacterial translocation in the neonate. Curr Opin Pediatr 6:327-333

47. Sarff LD, McCracken GH Jr and Schiffer MS 1975 Epidemiology of Escherichia coli $\mathrm{K} 1$ in healthy and diseased newborns. Lancet 17:1099-1104

48. el Mohandes AE, Keiser JF, Johnson LA, Refat M, Jackson BJ 1993 Aerobes isolated in faecal microflora of infants in the intensive care nursery: relationship to human milk use and systemic sepsis. Am J Infect Control 21:231-234 